\title{
Spinal Fusion with Methylmethacrylate Cage
}

\author{
Majid Reza Farrokhi and Golnaz Yadollahi Khales \\ Shiraz Neurosciences Research Center, Shiraz University of Medical Sciences, Shiraz, \\ Iran
}

\section{Introduction}

A brief history of anterior cervical decompression and fusion (ACDF) surgery is useful. The first reports on ventral approaches to cervical disc pathology appeared in the 1950s. Two most common methods for ACDF were described by Robinson and Smith in 1955 (1) and Cloward in 1958 (2). Robinson and Smith described a surgical procedure for removing cervical disc material in which a rectangular bone graft, obtained from the iliac crest, was replaced to allow a cervical fusion to develop. In Cloward's method, discectomy was performed by a dowel technique. Although numerous modifications have been made to this procedure since the 1950s, a great majority of spine surgeons currently use either the Cloward or the Robinson and Smith's technique. Now, this technique is used in special circumstances. Marked motor deficit or agonizing intractable radicular pain with an appropriate disc imaging is a Principal indication for expedient intervention in root syndromes. Additionally, a myelopathic picture from soft central sequestra is an ordinarily reason for prompt surgery. Chronic persistent brachialgia with nerve root symptoms appropriate to the findings obtained from imaging warrants surgical treatment. Surgery is also indicated if there is a tumor or infection that compresses the cord (3).

\subsection{History of spinal fusion}

In 1911, Albee (4) and Hibbs (5) used spinal fusion for stabilization. Although it was performed to prevent progressive spinal deformity in patients with Pott's disease, the procedure was later used to manage scoliosis and traumatic fractures. Hibbs' method, which was most frequently used, comprised harvesting an autologous bone graft from the laminae and overlaying the bone dorsally. Despite later improvements in this technique, the rate of pseudarthrosis especially in scoliosis remained unacceptably high (6). Robinson and Smith (1) described their technique in 1955 and Cloward (2) described his cervical fusion technique in 1958.

\subsection{Biology of spine fusion}

Each year, more than 185,000 spinal arthrodeses are performed in the United States that most of them are posterolateral lumbar intertransverse process fusions (7). There should be several factors working together to obtain a successful fusion including local environment of fusion, systemic factors, and possible use of fusion enhancers. 


\section{Graft properties}

Choosing graft material has profound implications for success or failure of an arthrodesis. The ideal graft is osteogenic, osteoinductive, and osteoconductive.

\subsection{Osteoinduction}

Osteoinduction is the stimulation of multipotential stem cells for differentiation into functioning osteogenic cells. This is mediated by growth factors in bone matrix itself. Both autogenous and allograft bone are osteoinductive (8).

\subsection{Osteogenicity}

Osteogenicity refers to the presence of viable osteogenic cells, either predetermined or inducible, within the graft. Only fresh autologous bone and bone marrow are osteogenic (9).

\subsection{Osteoconduction}

Osteoconductivity refers to a material's capacity to foster neovascularization and infiltration by osteogenic precursor cells via creeping substitution. It occurs on the scaffold provided by bone graft matrix.

\subsection{Connectivity}

Connectivity is the ability of an osteoconductive graft material to be connected to the local bone. This is determined by the surface area available for incorporation into the fusion mass.

\section{Graft material}

\subsection{Autograft}

Autogenous bone from iliac crest is the gold standard graft material. Historically, it has been the most successful graft source in spinal fusion. Cancellous autograft has the requisite matrix proteins, mineral, and collagen for the ideals of osteoinductivity, osteogenicity, and osteoconductivity. Nevertheless, there are significant drawbacks to autograft including procurement morbidity, limited availability, and increased operative time (10).

\subsection{Allograft}

The desire to avoid donor site morbidity led to increased use of allograft bone in spine surgery. Advances in procurement, sterilization, preparation, and storage made it practical. Although it was widely used in the spine surgery, there are still concerns regarding fusion rates and disease transmission. Allograft is not osteogenic because there is no surviving cell in the graft. Some osteoinductive potential of allograft is lost for processing and storage requirements of allograft. Although allograft is generally performed well in both cervical and lumbar interbody fusions in which the graft is subject to compression, the results of posterolateral lumbar environment with primarily tensile forces are not favorable. This has led many surgeons to use allograft as an autograft (11). However, there are some complications such as graft collapse, graft expulsion, graft site pain and infection, 
pseudarthrosis, spinal deformity, and poor fusion rate (12). The low stabilizing effect of bone grafts often requires further stabilization with anterior plates (13).

\subsection{Xenograft}

Taking bone graft from other species has been reported in the orthopedic literature (14). Despite processes of xenografts, they remain immunogenic and provoke a host response. The graft may be encapsulated with resultant blockade to be revascularized (15).

\section{Bone substitutes}

Because of these drawbacks in both autograft and allograft tissues, synthetic alternatives have been a very active area of research for the past 20 years. Nevertheless, only $10 \%$ of the 2.2 million bone graft procedures worldwide involve synthetics for the perceived inferiority to native autograft and allograft. Drawbacks of many synthetics include poor resorbability, inclusion of animal or marine-derived components, variable handling characteristics, limited availability, and increased cost (16).

\subsection{Ceramics}

Tricalcium phosphate $\left(\mathrm{Ca}_{3}\left(\mathrm{PO}_{4}\right)_{2}\right)$ ceramics including hydroxyapatite $(\mathrm{HA})$ and tricalcium phosphate (TCP) have been widely used in orthopedic and spine surgery (17). These osteoconductive, biodegradable materials are compatible with the remodeling of bone necessary to achieve optimal strength. Other non-resorbable materials remain in the fusion mass, leave permanent stress risers and prolong strength deficiencies. Synthetics should have several properties to be a useful graft material. $\mathrm{Ca}_{3}\left(\mathrm{PO}_{4}\right)_{2}$ ceramics are compatible with local tissues, remain chemically stable in body fluids, and should be able to withstand sterilization. (18) Furthermore, they should be available in different shapes and size, be costeffective, and have reliable quality control. These ceramics have been widely used in dentistry and maxillofacial surgery, (19) as well as in animal models (20). They are also used in humans and may be prepared as either compact or porous materials. Greater crystallinity and density of compact forms results in greater strength and resistance to dissolution in vivo. However, more porous versions which approximate the interconnectivity of cancellous bone enhance bone ingrowth at the expense of more rapid degradation. Natural coral is successfully used for augmentation or even replacement autograft (21). The calcium carbonate $\left(\mathrm{CaCO}_{3}\right)$ in coral is hydrothermally converted to $\mathrm{Ca}_{3}\left(\mathrm{PO}_{4}\right)_{2}$. The structural geometry of coral is similar to cancellous bone that makes it highly osteoconductive and connective.

\section{Non injectable ceramics}

Synthetic ceramics are osteoconductive but do not intrinsically possess any osteoinductive potential. The most common ceramics in current use are hydroxyapatite $\left[\mathrm{Ca}_{10}\left(\mathrm{PO}_{4}\right)_{6}(\mathrm{OH})_{2}\right]$, tricalcium phosphate $\left[\mathrm{Ca}_{3}\left(\mathrm{PO}_{4}\right)_{2}\right]$, calcium sulfate dihydrate $\left[\mathrm{CaSO}_{4} \cdot 2 \mathrm{H}_{2} \mathrm{O}\right]$, and combinations of that. In spite of exhibiting different chemical properties from tissue grafts, ceramics provide off-the-shelf availability of consistently high-quality synthetic materials with no biologic hazards. After incorporation, the strength of the repaired defect site is comparable to that of cancellous bone. Therefore, ceramics can be used as an alternative or an addition to either 
cancellous autograft or allograft, as cancellous bone void filler, bone graft extender, or in sites where compression is in a dominant mode of mechanical loading (22).

\subsection{Rapidly resorbing ceramics}

Scaffolds of tricalcium phosphate have two forms including a and $\beta$ that are formulated at $1200{ }^{\circ} \mathrm{C}$ and $800^{\circ} \mathrm{C}$, respectively (23). These forms have different crystalline structures but the same elemental and stoichiometric characteristics.

\subsection{Intermediate resorbing ceramics}

\subsection{1 $\beta$-Tricalcium phosphate}

An ultraporous $\beta$-tricalcium phosphate ( $\beta$-TCP) formulation, engineered using nanoparticle technology, has porosity comparable to natural cancellous bone (24).

\subsection{Slowly resorbing ceramics}

Hydroxyapatite is another ceramic that is readily available, but is associated with extremely slow remodeling. Slowly resorbing or nonresorbing material can interfere with remodeling and be the nidus of a mechanical stress point. Slow resorption and brittleness of hydroxyapatite make it less ideal for clinical use. Therefore, hydroxyapatite is often used in modified forms, for example, combining it with calcium carbonate to speed the rate of resorption (25).

\section{Injectable ceramics (calcium phosphate cement)}

In contrast to preformed solid constructs of calcium phosphate, so formed outside the body by manufacturing methods and subsequently placed by surgical intervention, liquid components can be injected directly into a bone defect site. This can then set into solid, defect filling, cement-like mass of calcium phosphate. Then it transforms slowly into bone in 3 to 4 years (26).The transformation of liquid components into a solid mass of calcium phosphate is achieved by well-known chemical reactions with a low-temperature exotherm. The resulting bone filler has a biologic response and compressive strength similar to cancellous bone (27) and promises some clinical applications such as adjunct treatment of vertebral body compression fractures and possibly the augmentation of pedicle screw fixation.

\section{Nonbiologic osteoconductive substrates}

Advantages of nonbiologic osteoconductive substrates include absolute control of final structure, no immunogenicity, and excellent biocompatibility (28). Some examples are degradable polymers, bioactive glasses, and porous metals such as tantalum.

\section{Spinal implants: Rigid versus dynamic}

Spinal implants can be described as rigid, dynamic, or hybrid. Dynamic implants provide some subsidence between segments. An advantage of a dynamic implant is that it can offset stress at the implant-bone interface and therefore does not provide stress shielding of the 
bone graft. The purpose of a rigid construct is to immobilize completely the spine. This is rarely achieved because of the properties of bone. Movement in a rigid system often increases with time through the weakening of the implant-bone interface. Repetitive movement under sufficient stress will eventually lead to failure at the interface, unless bony fusion first occurs. The goal of rigid fixation is only to hold long enough for bony fusion to take place. The purpose of a dynamic construct is to provide intersegmental subsidence.

\section{Stainless steel}

Stainless steel implants are iron and carbon-based alloys. Initial trials of stainless steels, as an implant, showed that preventing corrosion by aiding resistance to chloride degradation was insufficient (29).

\section{Titanium-based alloys}

Titanium-based alloys are currently the most commonly used alloys for bioimplantation. Titanium-based alloys are advantageous for several reasons. They have both high strength and fatigue resistance. Titanium based alloys also decrease stiffness compared to stainless steel. The reduction in the stiffness facilitates transfer of the stress at the bone-implant interfaces with alloy and can minimize bone resorption. Titanium-based alloys have higher fatigue strength compared to stainless steel. However, titanium alloys are vulnerable to any surface flaws. Any scratch or notch can rapidly accelerate the fatigue failure process. Titanium alloys also lack any known immunogenicity (30).

\section{Interbody cages}

A variety of prosthetic interbody cages are now available for use in the cervical spine, both for disc space arthrodesis and to bridge the larger voids created by single or multilevel corpectomy. Current devices are fabricated either from titanium alloy or polymer. Interbody cages are intended to confer immediate structural integrity to the ventral spine. Although some surgeons have placed them as naked implants, (31) more typically they are hollow, porous implants employed as carriers for osteoinductive or osteoconductive materials for securing long-term stability through biologic integration with the recipient spine. Some of their shortcomings are migration, subsidence, stenotic myelopathy, foreign body reactions and nonunion (32). Cages can also lead to computed tomography (CT) artifacts by obscuring interbody fusion.

\section{Polyetheretherketone (PEEK)}

PEEK cages have recently been used in cervical surgery. PEEK is polyetheretherketone, a semi-crystal polyaromatic linear polymer (33). PEEK is a non-absorbable biopolymer that has been used in a variety of industries including medical devices. The PEEK cages are biocompatible, radiolucent, and have modulus of elasticity similar to the bone. This distinguishing feature seems to be able to prevent cage subsidence induced by metallic cages (34). In an in vitro biomechanical study, the stiffness of the PEEK cage was statistically higher than that of the normal motion segment in flexion. Volume-related stiffness of the PEEK cage was higher than that of iliac bone in all directions. In addition to the fact that the 
PEEK cage is radiolucent and does not produce artifacts on radiographs or CT scans, it is easy to evaluate fusion status on X-ray films. It also induces cell attachment and fibroblast proliferation and increases the protein content of the osteoblasts (35). There was no foreign body reaction in our series (36).

\section{Bioabsorbable cages}

Synthetic, absorbable, polymeric devices represent a new class of materials for achieving interbody fusion in the spine. The materials are typically radiolucent, have a low modulus of elasticity similar to that of bone, and will be completely absorbed over time (from 6 weeks to 6 years). Their radiolucent nature improves image assessment of fusion healing, and their time-engineered resorption characteristics allow controlled dynamization in interbody and plate applications. However, their degradation elicits a mild inflammatory response and may in more severe cases cause osteolysis and/or sterile sinus drainage. Furthermore, an absorbable device would not be able to continue supporting the disc space in a pseudarthrosis. The clinical use of absorbable cervical spine cages made of $40 \%$ poly $(\mathrm{N}-$ vinylpyrrolidone comethylmethacrylate), $50 \%$ polyamide fibers and $10 \%$ calcium gluconate was first reported in 1989 with early positive results. However, subsequent studies have reported low fusion rates, a high incidence of device migration, lack of incorporation into the surrounding bone, and questionable resorption. More recently, absorbable devices made from 70:30 poly (L-lactide:D, Llactide) copolymer (PLDLA) have been investigated for spinal fusion (37).

\section{Biocompatibility}

All surgical procedures are associated with a disruption of normal anatomic tissue planes which results in an accumulation of exudative fluid, fibrin, platelets, and polymorphonuclear leukocytes. 3 to 5 days postsurgery, macrophages accumulate and remove the surgical debris. 10 days after surgery, the macrophages are no longer present and lymphocytes predominate. It is followed by fibroblasts which complete the cellular phase of healing. Ceramic implants are very biocompatible since the cellular response to wound healing is not significantly altered. However, immune system is activated in the presence of a metal implant. For most surgical constructs, stainless steel implants are sufficiently nonreactive to permit bone fusion before the deleterious consequences of the normal inflammatory response such as severe pain or loosening. Metal allergy is widely prevalent and well recognized. Metal ions alone will not stimulate the immune system. Linked with proteins, metals such as cobalt, chromium, and especially nickel are immunogenic. Osteolysis or periprosthetic bone loss may occur at an implant site. Structural remodeling of surrounding bone occurs in response to stress shielding. This bone destruction can lead to possible failure of the implant and loosening (38).

\section{History of bone cement}

The story of modern cements began with Otto Röhm's invention of polymethyl methacrylate (PMMA), a solid material with good biocompatibility that was named plexiglass, in the early 20th century. 
In 1943, polymerisation of PMMA became possible at room temperature. PMMA was used clinically for the first time in plastic surgery in the 1940s to close gaps in the skull. Comprehensive clinical tests of compatible bone cements with body were conducted before using them in surgery. The excellent tissue compatibility of PMMA allowed the use of bone cements for anchorage of head prostheses in the 1950s. In 1954, Idelberger (39) used PMMA to fill spinal defects.

In the 1960s, Charnley (40) began using bone cement in numerous patients for the fixation of both the femur and acetabulum. Later researchers came up with the idea of adding an antibiotic to cement to decrease the incidence of infection.

\section{Synthetic polymers}

Synthetic polymer production is a field of implant technology that is rapidly expanding. Polymers, commonly known as plastics, are typically very large molecules made from a large number of individual subunits called monomers. Polymers are chemical compounds formed by combining these smaller, repeating structural units. The subunits repeat in various patterns following principles similar to those of molecular biology. The covalent bonds in polymers have a Hexed length. The complex folding of polymers is created by weak hydrogen bond cross-links that permit unfolding and elongation. The two most commonly used polymers are PMMA and ultra-high molecular weight polyethylene (UHMWPE).Polymer can be made less flexible by stiffening the backbone molecular chain and increasing the cross-links. Numerous other properties can be influenced by chemical changes including density, crystallization, solubility, thermal stability, and strength. Ultrahigh molecular weight polyethylene has been extensively used in artificial joints for its favorable surface wear and creep properties. In spine surgery, PMMA has been extensively used because it causes additional polymerization when the powder and liquid are mixed. The intermediate phase of polymerization yields a doughy material that can be worked and shaped into complex defects before it hardens. PMMA has many molecular and macroscopic defects that contribute to its characteristically weak tensile strength. These defects originate in the powder phase that consists of microspheres. The microspheres are bound together as the methylmethacrylate (MMA) monomer (liquid phase) polymerizes into a matrix that incorporates the microspheres. The juncture between the powder phase microspheres and the liquid phase remains relatively weak even after hardening. Additionally, the polymer chains have a few cross-links. In light of these reasons, the polymerized PMMA has a low tensile strength. The advantages of bone cement (acrylic polymer) over bone grafts and other cages are long-term clinical experience, high immediate stability, low donor site morbidity (41), low subsidence rate (42), and only mild inflammatory reactions. Nevertheless, bone cement is associated with polymerization heat, cytotoxicity, and false bony fusion (43).

\section{Bone cement components}

Two primary components of bone cements are a powder consisting of copolymers based on the substance PMMA, and a liquid monomer, MMA. These two components are mixed at an approximate ratio of 2:1 to form PMMA cement. Exposure to light or high temperatures can cause premature polymerization of the liquid component. Therefore, hydroquinone is 
added as a stabiliser or inhibitor to prevent premature polymerization. A starter, di-benzoyl peroxide (BPO), is added to the powder and an initiator, mostly N-dimethyl-p-toluidine (DmpT), is added to the liquid to encourage the polymer and monomer to polymerise at room temperature (cold curing cement). A contrast agent is added to make the cement radiopaque. Commercially available cements use either zirconium dioxide $\left(\mathrm{ZrO}_{2}\right)$ or barium sulphate $\left(\mathrm{BaSO}_{4}\right)$. Zirconium dioxide is one hundred times less soluble than barium sulphate with less effect on the mechanical properties of cement.

Chlorophyll is added to Biomet Europe cements, the color makes the cement more easily visible in the operating room, especially during revision procedures. The powder component in our antibiotic-loaded bone cement additionally contains an antibiotic (such as gentamicin) or a combination of antibiotics (such as gentamicin and clindamycin).

\subsection{Kinds of bone cement}

Bone cements may be divided into two kinds including low and high viscosity.

\subsection{Low viscosity}

These cements have a long-lasting liquid or mixing phase which causes a short working phase. Consequently, the application of low viscosity cements requires strict adherence to application times.

\subsection{High viscosity}

These cements have a short mixing phase and lose their stickiness quickly. They cause a longer working phase which gives the surgeon more time to apply them.

\section{Polymerization}

When the polymer powder and monomer liquid are mixed together, the polymerization process begins. The polymerization process can be divided into four different phases: mixing, waiting, application and setting.

\subsection{Mixing phase}

In the mixing phase, the cement should be mixed homogeneously to minimize the number of pores. Vacuum mixing is shown to reduce the porosity of the cement and to increase its mechanical strength.

\subsection{Waiting phase}

During this phase, the cements achieve a suitable viscosity for delivery of bone cement. The cement is still sticky dough in this phase.

\subsection{Working phase}

The working phase is a period during which the cement and the implant can be introduced. The cement should not be sticky and its viscosity should be suitable for application. If 
viscosity is very low, the cement may not be able to withstand the bleeding pressure and prevent blood from entering the cement (44).

\subsection{Hardening phase}

The cement hardens and sets completely during this phase. Cement temperature, the operation room temperature as well as the body temperature all influence hardening phase.

\section{New acrylic cage}

This acrylic cage is composed of PMMA and methacrylate and designed based on an experimental ring-to-cylinder (45). The cage has a curved, round plate adjustable to the upper endplate of the cervical disc space. The cages have a long internal cross-section of $14 \mathrm{~mm}$ and a height of $5 \mathrm{~mm}$. The acrylic cage could be filled with 1 to $1.5 \mathrm{~mL}$ bone graft to be inserted into the disc space (fig.1). The acrylic cage showed significantly better distraction, higher biomechanical stiffness due to biomechanical properties of the acrylate polymer and cage design, lower range of motion in bending, and an early bony interbody fusion without major foreign body reaction compared to bone grafts (fig. 2,3). Subsidence is less frequent within bone cement than with titanium or peek cages. It is explained by larger graft surface and better restoration of lordosis with acrylic cage than bone grafts and progressive interbody fusion (46). Furthermore, it has fewer CT artifacts, no bone cement toxicity or no heat effects, but it possibly reduces some of the long-term complications of other cages.

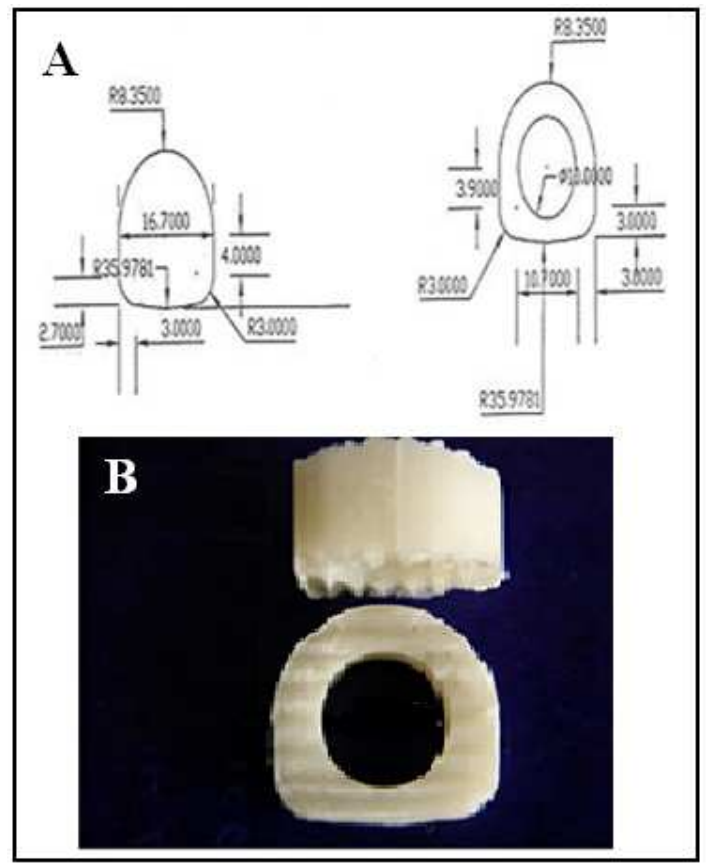

Fig. 1. A: Schematic drawing of acrylic cage. B: Photograph of interbody fusion cage designed to match the shape of cervical disc. 


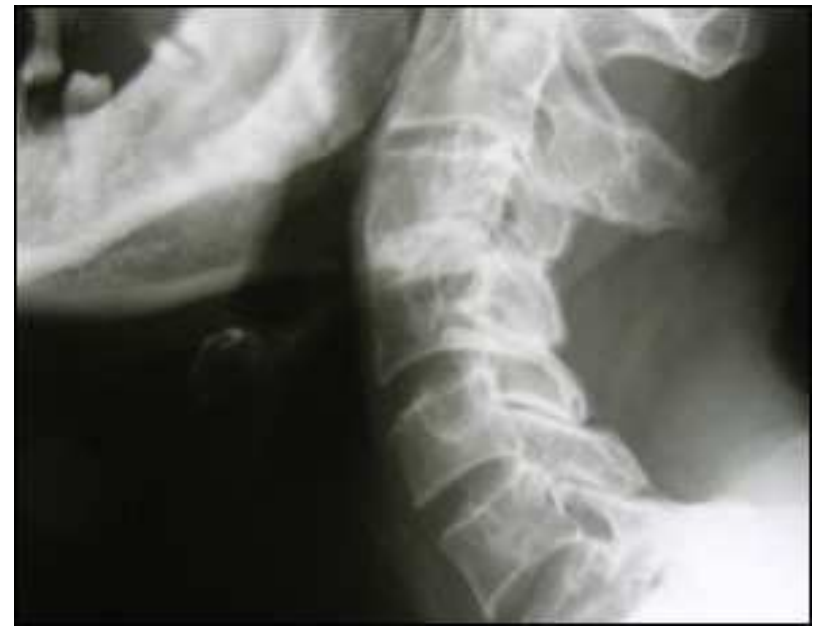

Fig. 2. Anterior cervical decompression and fusion (ACDF) with Acrylic cage at C3-C4 level extension view.

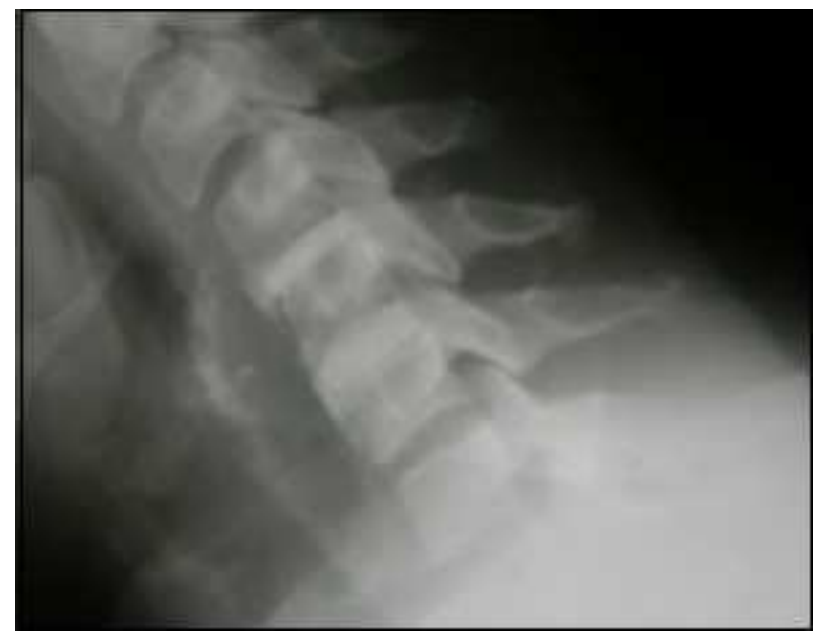

Fig. 3. Anterior cervical decompression and fusion (ACDF) with Acrylic cage at C4-C5 level FLx. vertebral.

\section{References}

[1] Robinson RA, Smith GW. Anterolateral cervical disc removal and interbody fusion for cervical disc syndrome. Bull john Hopkins Hasp1955; 95(1):223-224.

[2] Cloward RB. The anterior approach for removal of ruptured cervical disks. J Neurosurg 1958;15(6):602-17.

[3] Verbiest H, Paz y Geuse HD. Anterolateral surgery for cervical spondylosis in cases of myelopathy or nerve compression. J Neurosurg. 1966 ;25(6):611-22. 
[4] Albee FH. Transplantation of a portion of the tibia into the spine for Pott's disease: a preliminary report 1911. Clin Orthop Relat Res 2007;460:14-6.

[5] Hibbs RA. An operation for progressive spinal deformities. Clin Orthop Relat Res 2007;460:17-20.

[6] Cloward HB. The anterior approach for removal of ruptured cervical disks. J Neurosurg Spine 2007;6(5):496-511

[7] Boden S. Overview of the biology of lumbar spine fusion and principles for selecting a bone graft substitute. Spine 2002; 27(16 suppl 1):S26-S31.

[8] Urist MR. Bone formation by autoinduction. Clin Orthop Relat Res 2002 ;(395):4-10.

[9] Urist MR, Silverman BF, Büring K, et al. The bone induction principle. Clin Orthop Relat Res 1967;53:243-83.

[10] Laurie SW, Kaban LB, Mulliken JB, et al. Donor site morbidity after harvesting rib and iliac bone. Plast Reconstr Surg 1984;73(6):933-8.

[11] Friedlander G.Current concepts review: bone banking. j Bone joint Surg 1966;48:915-923.

[12] Sawin PD, Traynelis VC, Menezes AH. A comparative analysis of fusion rates and donor-site morbidity of ontogenetic rib and iliac crest bone graft in posterior cervical fusion. J Neurosurg 1998;88: 255-265.

[13] Geisler FH, Caspar W, Pitzent T. Reoperation in patients after anterior cervical plate stabilization in degenerative disease. Spine (Phila Pa 1976). 1998 Apr 15;23(8):911-20.

[14] Prolo DJ, Rodrigo JJ. Contemporary bone graft physiology and surgery. Clin Orthop Relat Res 1985;(200):322-42.

[15] Harmon PH. Processed heterologous bone implants (Boplant, Squibb) as grafts in surgery. Acta Orthop Scand 1964;35:98-116.

[16] Lewandrowski KU, Gresser JO, Wise OL, et al. Bioresorbable bone graft substitutes of different osteoconductivities: a histologic evaluation of osteointegration of poly(propylene glycol-co-fumaric acid)-based cement implants in rats. Biomaterials. 2000 Apr;21(8):757-64.

[17] Bucholz R, Carlton A, Holmes R. Hydroxyapatite and tricalcium phosphate bone graft substitutes. Orthop Clin North Am. 1987 Apr;18(2):323-34.

[18] Flatley T, Lynch K, Benson M. Tissue response to implants of calcium phosphate ceramic in the rabbit spine. Clin Orthop Relat Res 1983;(179):246-52.

[19] Coviello J, Brilliant J. A preliminary study on the use of tricalcium phosphate as an apical barrier. J Endod 1979;5(1):6-13.

[20] Holmes R. Bone regeneration within a coralline hydroxyapatite implant. Plast Reconstr Surg 1979;63(5):626-33.

[21] Guillemin G, Meunier A, Dallant P, et al. Comparison of coral resorption and bone apposition with two natural corals of different porosities. J Biomed Mater Res 1989;23(7):765-79.

[22] Gazdag AR, Lane JM, Glaser D, et al. Alternatives to autogenous bone graft: efficacy and indications. J Am Acad Orthop Surg1955: 3(1):1-8.

[23] Cazeau C, Doursounian L, Touzard RC. Use of ceramics of calcum triphosphate in the repair of tibial plateau fractures: a series of 20 cases. European Journal of Orthopaedic Surgery \& Traumatology 1999; 9 (3):171-174.

[24] Kon E, Muraglia A, Corsi A, et al. Autologous bone marrow stromal cells loaded onto porous hydroxyapatite ceramic accelerate bone repair in critical-size defects of sheep long bones. J Biomed Mater Res 2000;49(3):328-37.

[25] Fleming JE Jr, Cornell CN, Muschier GF. Bone cells and matrices in orthopedic tissue engineering. Orthop Clin North Am 2000;31(3):357-74. 
[26] Sanchez-Sotelo J, Munuera L, Madero R. Treatment of fractures of the distal radius with a remodellable bone cement: a prospective, randomised study using Norian SRS. J Bone Joint Surg Br 2000;82(6):856-63.

[27] Constantz BR, Ison IC, Fulmer MT, et al. Skeletal repair by in situ formation of the mineral phase of bone. Science 1995;267(5205):1796-9.

[28] Cornell CN. Osteoconductive materials and their role as substitutes for autogenous bone grafts. Orthop Clin North Am 1999;30(4):591-8.

[29] Rae T. The toxicity of metals used in orthopaedic prosthesis. An experimental study using cultured human synovial fibroblasts. J Bone Joint Surg Br 1981;63-B(3):435-40.

[30] Jacobs JJ, Gilbert JL, Urban RM. Corrosion of metal orthopaedic implants. J Bone Joint Surg Am 1998;80(2):268-82.

[31] Lange M, Philipp A, Fink U, et al. Anterior cervical spine fusion using RABEA-TitanCages avoiding iliac crest spongiosa: first experiences and results. Neurol Neurochir Pol 2000;34(6 Suppl):64-9.

[32] Majd ME, Vadhva M, Hott RT. Anterior cervical reconstruction using titanium mesh cages with anterior plating. Spine (Phila Pa 1976). 1999 Aug 1;24(15):1604-10.

[33] Cho DY, Liau WR, Lee WY, et al. Preliminary experience using a polyetheretherketone (PEEK) cage in the treatment of cervical disc disease. Neurosurg.2002: 51(6):1343-50.

[34] Jen-Chung Liao, Chi-Chien Niu,Wen-Jer Chen, et al. Polyetheretherketone (PEEK) cage filled with cancellous allograft in anterior cervical discectomy and fusion. Int Orthop 2008; 32(5):643-8.

[35]. Petillo O, Peluso G, Ambrosio L, et al. In vivo induction of macrophage Ia antigen (MHC class II) expression by biomedical polymers in the cage implant system. J Biomed Mater Res1994; 28(5):635-46.

[36] Kahraman s, Daneyemez m, Kayali h, et al. Polyetheretherketone(Peek) Cages For Cervical Interbody Replacement:Clinical Experience. Turkish Neurosurgery 2006;16(3) 120-123.

[37] Slivka MA, Spenciner DB, Seim HB , et al. High Rate of Fusion in Sheep Cervical Spines Following Anterior Interbody Surgery With Absorbable and Nonabsorbable Implant Devices. Spine (Phila Pa 1976). 2006 Nov 15;31(24):2772-7.

[38] Hedman T, Kostuik J, Fernie G, et al. Design of an intervertebral disc prosthesis. Spine (Phila Pa 1976). $1991 ; 16(6$ Suppl):S256-60

[39] Idelberger K. Treatment of spinal tuberculosis Munch Med Wochenschr 1954;96(8):192-4.

[40] Charnley J. The classic: The bonding of prostheses to bone by cement. 1964. Clin Orthop Relat Res 2010;468(12):3149-59.

[41] Fathie K. Anterior cervical diskectomy and fusion with methylmethacrylate. Mt Sinai J Med 1994;61:246-247.

[42] Wilke HJ, Kettler A, Goetz C, et al. Subsidence resulting from simulated postoperative neck movements. Spine (Phila Pa 1976). 2000 Nov 1;25(21):2762-70.

[43] Kettler A, Wilke HJ, Claes L. Effect of neck movements on stability and subsidence in cervical interbody fusion, an in vitro study. J Neurosurg 2001 ;94(1 Suppl):97-107.

[44] Wilkinson JM, Eveleigh R, Hamer AJ, et al. Effect of mixing technique on the properties of acrylic bone-cement: a comparison of syringe and bowl mixing systems. J Arthroplasty 2000;15(5):663-7.

[45] Farrokhi MR, Torabinezhad S, Ghajar KA. Pilot study of a new acrylic cage in a dog cervical spine fusion model. J Spinal Disord Tech 2010;23(4):272-7.

[46] Kulkarni AG, Hee HT, Wong HK. Solis cage (PEEK) for anterior cervical fusion: preliminary radiological results with emphasis on fusion and subsidence. Spine J 2007;7(2):205-9. 


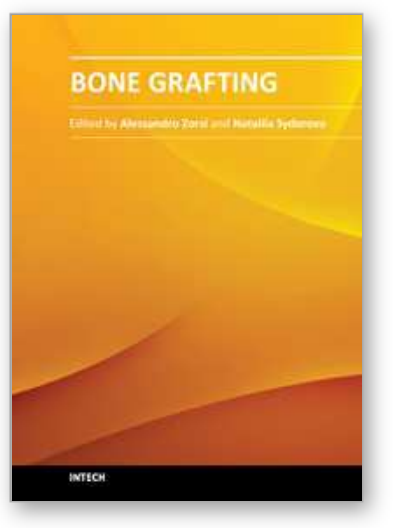

\author{
Bone Grafting \\ Edited by Dr Alessandro Zorzi
}

ISBN 978-953-51-0324-0

Hard cover, 214 pages

Publisher InTech

Published online 21, March, 2012

Published in print edition March, 2012

Bone grafting is the surgical procedure in which new bone (bone graft) or a replacement material (graft substitute), is placed into bone fractures or bone defects to aid in healing. Bone grafting is in the field of interest of many surgical specialties, such as: orthopedics, neurosurgery, dentistry, plastic surgery, head and neck surgery, otolaryngology and others. In common, all these specialties have to handle problems concerning the lack of bone tissue or impaired fracture healing. There is a myriad of surgical techniques nowadays involving some kind of bone graft or bone graft substitute. This book gathers authors from different continents, with different points of view and different experiences with bone grafting. Leading researchers of Asia, America and Europe have contributed as authors. In this book, the reader can find chapters from the ones on basic principles, devoted to students, to the ones on research results and description of new techniques, experts will find very beneficial.

\title{
How to reference
}

In order to correctly reference this scholarly work, feel free to copy and paste the following:

Majid Reza Farrokhi and Golnaz Yadollahi Khales (2012). Spinal Fusion with Methylmethacrylate Cage, Bone Grafting, Dr Alessandro Zorzi (Ed.), ISBN: 978-953-51-0324-0, InTech, Available from: http://www.intechopen.com/books/bone-grafting/spinal-fusion-with-methylmethacrylate-cage

\section{INTECH}

open science | open minds

\author{
InTech Europe \\ University Campus STeP Ri \\ Slavka Krautzeka 83/A \\ 51000 Rijeka, Croatia \\ Phone: +385 (51) 770447 \\ Fax: +385 (51) 686166 \\ www.intechopen.com
}

\author{
InTech China \\ Unit 405, Office Block, Hotel Equatorial Shanghai \\ No.65, Yan An Road (West), Shanghai, 200040, China \\ 中国上海市延安西路65号上海国际贵都大饭店办公楼 405 单元 \\ Phone: +86-21-62489820 \\ Fax: $+86-21-62489821$
}


(C) 2012 The Author(s). Licensee IntechOpen. This is an open access article distributed under the terms of the Creative Commons Attribution 3.0 License, which permits unrestricted use, distribution, and reproduction in any medium, provided the original work is properly cited. 